\title{
Kesantunan Imperatif pada Masyarakat Madura di Pasar Ikan Desa Kota Kulon, Kabupaten Bondowoso
}

\author{
Retno Dyah Susilaningtyas, Bambang Wibisono, Budi Suyanto \\ Jurusan Sastra Indonesia, Fakultas Ilmu Budaya, Universitas Jember \\ retnodyah010@gmail.com
}

Diterima 20 Desember 2017/Disetujui 20Desember 2017

\begin{abstract}
There is an imperative action on social interaction in the fish market. The interaction between traders, buyers, retailers, and porters. This acts dimension of politeness. Actual action are very bound by context. Using a pragmatic approach, this article examines the imperative action that apply to Madurese communities in the fish market in Kota kulon, Bondowoso, East Java. The data of this research is imperative speech acts spoken by the subject of research. Data is analytically analyzed according to the shape and scale of politeness. The result of the research shows that there are three ways to realize imperative action, that is using command sentence (imperative), declarative sentence, and interrogative. In detail there are six ways in realizing imperative action using imperative sentence, that is, using imperative sentences of command, solicitation, prohibition, request, order, decree, declarative, and interrogative sentence. The act of imperative using imperative sentence is considered polite if by superiors to subordinates. Subordinates to superiors can use imperative sentences if their relationships are very familiar and in informal situations. However, in general, the delivery of imperative actions using imperative sentences is considered less polite than the use of interrogative and declarative sentences. In addition, the use of particles of $y a h, r a$, and $k o$ in Madurese is used as an affirmation and measuring tool of politeness. Particle yah functioned to soften the speech, $r a$ particles used when the opponent said to do two errors, and $k o$ used when the opponent said to make mistakes repeatedly. In this study no particles found yah, $r a$, and ko used by subordinates to superiors.
\end{abstract}

Keywords: imperative civility, imperative speech acts, social interactions, imperative sentences, interrogative sentences, and declarative sentences.

\section{Pendahuluan}

Pasar adalah salah satu tempat terjadinya intaraksi sosial. Dalam interaksi sosial tersebut muncul tindak imperatif yang tidak terlepas oleh kaidah sosial dan kultural. Dampak yang diterima jika kaidah sosial dilanggar akan mendapat kerugian, sebaliknya jika ditaati akan mendapatkan keuntungan. Hal tersebut disebabkan oleh kedudukan manusia sebagai makluk sosial, manusia saling bekerja sama untuk mencapai tujuan individu dan tujuan bersama. Selain itu, manusia harus menunjukkan solidaritas, toleransi, dan saling menghargai kepada sesama. Dalam mencapai tujuan tersebut manusia harus berinteraksi dengan sesamanya. Beberapa peranan masyarakat pasar seperti, pedagang, pembeli, pengecer, dan kuli, memiliki keterkaitan antara satu dengan lainnya. 
Dari interaksi tersebut memungkinkan munculnya tindak imperatif. Komunikasi imperatif memiliki fungsi signifikan. Sesuai dengan pendapat Kunjana (2009:1) yang menyatakan bahwa entitas imperatif menarik untuk dicermati, diteliti, dikaji, dan diperikan. Tindak imperatif tidak terlepas oleh kaidah sosial dan kultural. Ada beberapa cara yang dapat digunakan untuk mewujudkan tindak imperatif yaitu dengan menggunakan kalimat imperatif perintah, suruhan, permintaan, permohonan, desakan, bujukan, imbauan, persilaan, ajakan, umpatan, pemberian ucapan selamat, anjuran, dan imperatif ngelulu (Kunjana, 2005:93-117). Kalimat tersebut dituturkan dengan menggunakan kalimat imperatif, interogatif, dan deklaratif. Dalam penerapannya, tindak imperatif memiliki tingkat kesantunan yang berbeda-beda. Kesantunan merupakan perilaku linguistik atau perilaku lainnya yang digunakan untuk mencapai tujuan (Leech, 1993:161). Dalam masyarakat pasar kesantunan berbahasa digunakan untuk menanggapi adanya maksud penggunaan tindak imperatif yang digunakan oleh penutur kepada lawan tutur.

\section{Metode Penelitian}

Penelitian ini menggunakan rancangan deskriptif kualitatif. Menurut Djajasudarma (2011:11) penelitian kualitatif adalah tradisi tertentu dalam ilmu pengetahuan sosial yang secara fundamental bergantung pada pengamatan manusia dalam kawasannya sendiri dan berhubungan dengan masyarakat tersebut melalui bahasanya. Deskripsi kualitatif digunakan oleh peneliti untuk mengungkap permasalahan yang berusaha dipecahkan dalam penelitian ini. Lokasi penelitian di pasar ikan Desa Kota Kulon, Kabupaten Bondowoso. Sumber data dalam penelitian ini ialah masyarakat Madura yang sedang berada di pasar ikan Desa Kota Kulon, Kabupaten Bondowoso. Masyarakat pasar di antaranya berperan sebagai pedagang, pembeli, pengecer, dan kuli. Penyediaan data menggunakan metode simak dengan teknik dasar sadap, kemudian menggunakan teknik lanjutan simak libat cakap (SLC), rekam, dan catat. Peneliti juga menggunakan metode cakap untuk mengimbangi penggunaan SLC, teknik dasar pancing. Kemudian menggunakan teknik lanjutan cakap semuka, rekam, dan catat. Hasil analisis data penelitian ini disajikan menggunakan cara informal.

\section{Hasil Pembahasan}

Hasil yang diperoleh dari penelitian ini, menunjukkan bahwa tindak imperatif sering digunakan oleh masyarakat di pasar ikan Desa Kota Kulon, Kabupaten Bondowoso, saat berlangsungnya interaksi sosial. Dalam penerapannya, tindak imperatif menggunakan kalimat imperatif, interogatif, dan deklaratif. Ketika kalimat tersebut yang digunakan untuk mengungkap tindak imperatif perintah, suruhan, permintaan, permohonan, desakan, bujukan, imbauan, persilaan, ajakan, umpatan, pemberian ucapan selamat, anjuran, dan ngelulu.

Tindak imperatif tersebut sering digunakan oleh atasan kepada bawahan, namun muncul kemungkinan dilakukan oleh bawahan kepada atasan, jika mereka memiliki hubungan yang sangat dekat. Berikut adalah contoh tindak imperatif yang dituturkan oleh atasan kepada bawahan dan bawahan kepada atasan yang penyampaiannya menggunakan kalimat imperatif, interogatif, dan deklaratif. Kita perhatikan kutipan-kutipan berikut. 


\subsection{Tindak Imperatif Menggunakan Kalimat Imperatif}

Berikut adalah realisasi tindak imperatif menggunakan kalimat imperatif yang dilakukan oleh masyarakat Madura di pasar ikan di Desa Kota Kulon, Kabupaten Bondowoso. Kalimat imperatif yang digunakan ada bermacam-macam, yaitu sebagai berikut.

Konteks: tuturan disampaikan oleh pengecer (C), usia 42 tahun, kepada kuli yang disimbolkan dengan D (usia 45 tahun). Kedua penutur telah lama kenal, tuturan terjadi pada pukul 13.20 WIB. C menghampiri D yang berada di warung mengingatkan D, mengenai pemisahan lima ikat ikan saat mobil pengangkut ikan pengangkut ikan telah datang.

Tuturan:

C: Mad, mon juko'en la dâteng jhâ lopa le-lèma' èpalaèn!

[Mad, mon la ḍaten juks?en jhâ? loppa s€ lel€ma? €plaa€n ]

'Mad, kalau ikannya sudah datang jangan lupa lima dilainkan!'

D: Jâriya la ḍ̂teng

[J ${ }^{\mathrm{B}}$ riya la dateๆ.]

'Itu sudah datang!'

C: Abee... la dâteng juko'en.

[Abee...la d़ ${ }^{\mathrm{p}}$ ten juks?en]

'Lho...sudah datang ikannya'

D: Mara berkak, e berkak e!

[Ayo lari, ayo lari!]

'Ayo lari, ayo lari!'

Tindak imperatif dalam kutipan tersebut direalisasikan dengan penggunaan kalimat imperatif perintah, yaitu yang dituturkan oleh $\mathrm{C}$ kepada D. C memerintah D untuk menurunkan ikan, $\mathrm{C}$ yang memahami merespons tuturan tersebut dengan tindakan mempersiapkan diri untuk menurunkan ikan. Tuturan tersebut dianggap kurang santun, jika diukur menggunakan skala ketidaklangsungan tuturan, karena kedudukan $\mathrm{C}$ lebih rendah daripada D. Akan tetapi, jika diukur menggunaakn jarak sosial, tuturan tersebut santun, karena $\mathrm{C}$ dan $\mathrm{D}$ memiliki hubungan sosial yang sangat dekat. Selanjutnya, kita perhatikan kutipan berikut.

Konteks: tuturan disampaikan oleh pengecer yang disimbolkan dengan C (usia 42 tahun) kepada pembeli yang disimbolkan dengan B (usia 36 tahun). Kedua penutur telah lama kenal, tuturan terjadi pada pukul 13.43 WIB. Dalam tuturan, B menanyakan harga ikan terri. $\mathrm{C}$ merespons dengan menjawab harga ikan dan menyuruh B segera memilih ikan.

Tuturan:

B: Mon sè ennem bigghi' senapa?

[Mən s€ ənnəm biggh i? senapa]

'Kalau yang enam buah berapa?'

C: Dupolo dhuwe', la ongghâ satèya, Yu.

[Dupolo $\mathrm{d}^{\mathrm{h}}$ uwe?, la ong ${ }^{\mathrm{h}}$ sateya, Yu]

'Dua puluh dua, sudah naik sekaranng, Mbak.' 


\section{B: Dupolo yâ??}

[Dupolo $\mathrm{y}^{\mathrm{e}}$ ?]

'Dua puluh ya?'

C: Ta' bhisa, jeriya la modâ! Mon endâ' mayuh ècatetah bi' ghula!

[Ta? $\mathrm{b}^{\mathrm{h}}$ isa, jəriya la mod ${ }^{\mathfrak{b}}$, mon ənd $^{\mathrm{E}}$ ? Mayuh $\epsilon$ cateta bi? $\left.\mathrm{g}^{\mathrm{h}} \mathrm{ula}\right]$

'Tidak bisa, itu sudah murah! Kalau mau, ayo saya catet!'

B: (diam)

Tindak imperatif pada kutipan ini dinyatakan menggunakan kalimat imperatif ajakan yang dituturkan oleh C kepada B. C memerintah D dengan cara mengajak B untuk segera memilih ikan, memahami hal tersebut B lalu melakukan tindakan melakukan, yaitu tindakan memilih ikan. Hal tersebut sesuai dengan keinginan $\mathrm{C}$. Tuturan tersebut dianggap kurang santun, jika diukur menggunakan skala ketidaklangsungan tuturan. Namun, diukur menggunakan jarak sosial, tuturan tersebut dianggap santun, karena $\mathrm{C}$ dan $\mathrm{B}$ memiliki hubungan sosial dekat, telah lama saling mengenal, dan sering bertemu. Tuturan semacam itu tidak menimbulkan disharmoni sosial antara C dan B. Kita perhatikan lagi kutipan berikut ini.

Konteks: tuturan disampaikan oleh kuli pertama yang disimbolkan dengan D1 (usia 29 tahun) kepada kuli kedua yang disimbolkan dengan D2 (usia 31 tahun). Kedua penutur telah lama kenal, tuturan terjadi pada pukul 14.25 WIB. Susana pasar ramai. Dalam tuturan, D1 memerintah D2 agar tidak menurunkan ikan terlebih dahulu. Perintah tersebut diperoleh D1 dari pedagang ikan.

Tuturan:

D1:Elun...elun..., jhâ' èpatoron ghelun can!

[əlun...əlun..., $\mathrm{j}^{\mathrm{h}}{ }^{\mathrm{r}}$ ? epetoron ghəlun can.]

'Tunggu...tunggu..., jangan diturunkan dulu katanya.'

D2: iyâh la taoh.

[iy'h la taoh.]

'Iya sudah tahu.'

Tindak imperatif dalam kutipan ini direalisasikan menggunakan kalimat imperatif larangan yang dituturkan oleh D1 kepada D2. D1 memerintah D2 agar tidak menurunkan ikan terlebih dahulu, memahami perintah yang tuturkan oleh D1, D2 menyanggah dan melakukan tindakan menunggu. Tuturan tersebut dianggap kurang santun, jika diukur menggunakan skala ketidaklangsungan. Akan tetapi, jika diukur menggunakan jarak sosial, tuturan tersebut dianggap santun, karena D1 dan D2 memiliki status sosial setara, keduanya merupakan sesama kuli. Kutipan berikut adalah realisasi tindak imperatif tidak menggunakan kalimat imperatif larangan, tetapi menggunakan kalimat imperatif permintaan.

Konteks: tuturan disampaikan oleh pembeli yang disimbolkan dengan B (usia 36 tahun) kepada pengecer yang disimbolkan dengan $\mathrm{C}$ (usia 42 tahun). Kedua penutur telah lama kenal, tuturan terjadi pada pukul 14.32 WIB. B meminta C agar tidak memberi ikan dengan jumlah banyak, namun $\mathrm{B}$ menyanggah tuturan $\mathrm{C}$ dengan menolak jumlah yang ditawarkan.

Tuturan: 
B: Si bitong, Si!

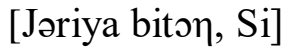

'Si hitung, Si!'

C: Ta' korang Sri, kibè be-bellu' la yâ?

[Ta? koraך Sri, kib€ bə-bəllu? la ${ }^{\mathrm{e}}$ ]

'Tidak kurang Sri, bawa delapan ya?'

B: Ella jha' nya'- benya' Si, pa'empa' bei lah ya? Tako 'ta' abi'.

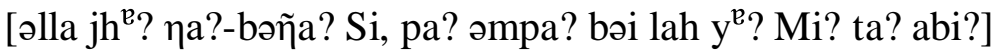

'Jangan banyak-banyak Si, empat saja ya? Takut tidak habis.'

C: Iyâh.

$\left[\mathrm{Iy}^{\mathrm{B}} \mathrm{h}\right.$ ]

'Iya.'

Tindak imperatif di atas termasuk kalimat imperatif permintaan yang dituturkan oleh B kepada C. B memerintah C dengan meminta agar tidak menambahkan jumlah ikan yang dibeli oleh B. C yang memahami tindak imperatif tersebut langsung mengambil tindakan untuk tidak menamhakan ikan. Tuturan tersebut dianggap tidak santun, jika diukur menggunakan skala ketidaklangsungan. Namun, jika diukur menggunakan variabbel status sosial, tuturan tersebut dianggap santun, karena status sosial B lebih tinggi daripada $\mathrm{C}$, dan jarak sosial di antara mereka relatif dekat.

Konteks: tuturan disampaikan oleh pengecer pertama yang disimbolkan dengan $\mathrm{C} 1$ (usia 42 tahun) kepada pengecer kedua yang disimbolkan dengan C2 (usia 38 tahun). Kedua penutur telah lama kenal, tuturan terjadi pada pukul 11.05 WIB. Suasana pasar sepi, C1 melihat teman-teman di kantin pasar sedang makan manga. Kemudian $\mathrm{C} 1$ mengetahui bahwa $\mathrm{C} 2$ yang membawa mangga, $\mathrm{C} 1$ langsung meminta mangga kepada C2. C2 memerintah C1 untuk meminta mangga tersebut di teman-teman yang telah diberi mangga oleh $\mathrm{C} 2$.

Tuturan:

C1: Can ngibe pao ben? Menta ko'!

[Can nibə pas bən? Menta kə?]

'Katanya kamu membawa manga? Saya mau minta.'

C2: Je' la eberri' gelle'!

[Jə? la єbərri? gəllə?]

'Kan sudah diberi tadi!'

C1: Dimma? jhả 'ékala' na'-kana'!

[Dimma J ${ }^{\mathrm{h}}$ ? €kala? na?-kana?]

'Dimana, sudah diambil oleh anak-anak!'

C2: Ngibe bennya' ko'! Apanah se tảdả'? Jie apah sé éteggu' na'-kana'?

[nibə bəñ̃a? ko?! Apana ${ }^{\mathrm{h}}$ sє tad ${ }^{\mathrm{e}}$ ? Jiə apa ${ }^{\mathrm{h}}$ sє €təggu? Na?-kana?]

'Saya bawa banyak! Apanya yang habis? Apa itu yang dipegang oleh anak-anak?'

C1: Palang, ééreb bhi' na'-kana'!

[Palay, $\epsilon \in \mathrm{r} \partial \mathrm{b} \mathrm{b}^{\mathrm{h}} \mathrm{i}$ ? na?-kana?]

'Gawat, disembunyikan dengan anak-anak!'

Tindak imperatif dalam kutipan ini direalisasikan dengan kalimat imperatif suruh yang dituturkan oleh $\mathrm{C} 2$ kepada $\mathrm{C} 1$. C2 menyuruh $\mathrm{C} 1$ untuk memirksa rekan kerja yang telah diberi oleh 
$\mathrm{C} 2$. Memahami tuturan $\mathrm{C} 2, \mathrm{C} 1$ melakukan tindakan memeriksa mangga yang ada di rekan kerja. Tuturan tersebut dianggap santun, jika diukur menggunakan skala ketidaklangsungan. C2 menggunakan tuturan nonimperatif untuk mengungkap tindak imperatif suruh. Jika diukur menggunakan jarak sosial tuturan tersebut juga dianggap santun. Hal tersebut disebabkan C2 dan $\mathrm{C} 1$ memiliki status sosial dekat, keduanya merupakan pengecer. Kutipan berikut adalah realisasi tindak imperatif menggunakan kalimat imperatif ngelulu.

Konteks: tuturan disampaikan oleh pengecer yang disimbolkan dengan $\mathrm{C}$ (usia 42 tahun kepada pembeli yang disimbolkan dengan B (usia 50 tahun). Pukul 12.12 WIB. C melihat B yang kembali ke stan berjualannya. C melihat B mencari-cari ikan, mengetahui hal tersebut $\mathrm{C}$ menegur $\mathrm{B}$, untuk menanyakan ikan yang dicari.

Tuturan:

C: Arapah kang? [arapa $\left.{ }^{\mathrm{h}} \mathrm{ka \eta}\right]$ 'Kenapa mas?'

B: Ghi' buruh bâdâ, jhâ' la èbitong bhi' engko'. Bhi' engko' èdhina èdinna', engko' alènglèng, pas ko' bâlik tâdâ' karè tetello' bhai.

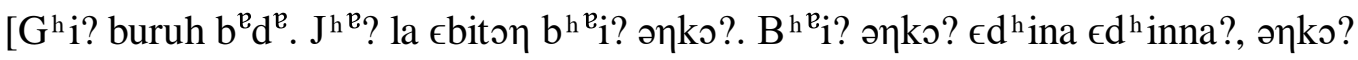

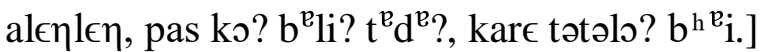

'Tadi masih ada, sudah saya hitung. Saya taruh di sini, kemudian saya berkeliling, ketika saya kembali sudah tidak ada, tinggal tiga.'

C: Abeh...ma' ta' benta, mon benta ta' epâsettong bhi' ghulâ. Ade' telas kang, maap. Mon enjhâ, jeriya tetelo' kala' la mi'èlang polè!

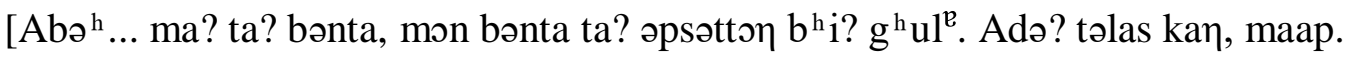

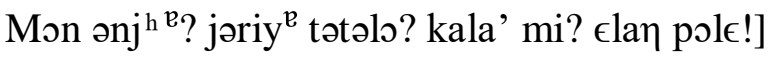

'Abeh...kok tidak bilang, kalau bilang tidak saya satukan. Habis Mas, maaf. Kalau tidak itu tiga-tiganya bisa diambil saja, takut terjual lagi.'

Tindak imperatif dalam kutipan ini direalisasikan dengan kalimat imperatif ngelulu yang dituturkan oleh B kepada C. B memerintah C dengan menggunakan ngelulu, yaitu tindakan tersebut diperkirakan sering terjadi. $\mathrm{C}$ yang memahami tuturan tersebut melakukan tindak mencari dan menyanggah tuturan B untuk lebih berhati-hati. Tuturan tersebut dianggap santun, jika diukur menggunakan skala ketidaklangsungan. Jika diukur menggunakan jarak sosial tuturan tersebut juga dianggap santun. Hal tersebut disebabkan B dan C memiliki status sosial dekat. Selanjutnya kita perhatikan kutipan berikut ini.

Konteks: tuturan disampaikan oleh kuli pertama yang disimbolkan dengan D1 (usia 31 tahun) kepada kuli kedua yang disimbolkan dengan D2 (usia 45 tahun). Kedua penutur telah lama kenal, tuturan terjadi pada pukul 18.02 WIB. Suasana pasar semakin sepi, para kuli mulai menaikan ikan ke atas mobil pengangkut ikan. D1 dan D2 telah selesai menaikan seluruh ikan dan tugas mereka selanjutnya mengikatkan tali pada setiap bahu mobil yang kemudian dibentuk melintang.

Tuturan:

D1: Tarè'- tarè sè kuat Wi, jha'biasana ben kuat. Juh tarè! 
[Tarє?-tar€? sє kuat Wi, Jh a? biasana bən kuat. Juh tarє?]

'Tarik-tarik yang kuat Wi, kamu biasanya kuat. Ayo tarik!

D2: (diam)

D1: Nah, jie pèntèr.

[Nah, jiə pєntєr]

'Nah, itu pintar.'

Tindak imperatif dalam kutipan ini tidak direalisasikan menggunakan kalimat deklaratif, tetapi menggunakan kalimat imperatif suruh yang dituturkan oleh D1 kepada D2. D1 memerintah D2 menarik tali yang digunakan untuk pengaman ikan-ikan yang berada di atas mobil pengangkut. D2 yang memahami hal tersebut melakukan tindakan yang diinginkan oleh D1. Tuturan tersebut dianggap santun, jika diukur menggunakan skala ketidaklangsungan. D1 menggunakan tuturan non imperatif untuk mengungkap tindak imperatif bujukan. Jika diukur menggunakan jarak sosial, tuturan tersebut juga dianggap santun. Hal tersebut disebabkan D1 dan D2 memiliki status sosial dekat, keduanya merupakan kuli.

\subsection{Tindak Imperatif Menggunakan Kalimat Deklaratif}

Kutipan berikut yang menunjukkan bahwa tindak imperatif tidak hanya direalisasikan dengan kalimat imperatif, tetapi ada yang direalisasikan dengan menggunakan kalimat deklaratif. Berikut adalah contohnya.

Konteks: tuturan disampaikan oleh pengecer yang disimbolkan dengan C (usia 42 tahun) kepada pembeli yang disimbolkan dengan B (usia 36 tahun). Kedua penutur telah lama kenal, tuturan terjadi pada pukul 12.25 WIB. Suasana pasar ramai. C ditugaskan oleh pedagang untuk melihat ikan yang ditawarkan oleh pedagang lain. B yang melihat $\mathrm{C}$ berjalan menuju arah utara, langsung menyapa dan ingin membayar setoran ikan.

Tuturan:

B: Ni-benien melolo, mon benta sè teppa'! Mara ko’ berempa? Tèngghu

Rahmad ta' ni benien, mon lakoh ya lakoh ta' gheje' melolo.

[Ni-bəniən mələlo mon bənta səppa? Mara ko? bərəmpa? ni-bəniən, mon lakıh ya lakoh ta? $\mathrm{g}^{\mathrm{h}}$ əjə? mələlə]

'Banyak bicara, kalau bicara yang benar. Liat Suhat tidak banyak

bicara, kalau kerja ya kerja tidak bercanda terus.]'

C: Kejje' Yu, mara ra ko' ghi' benta bhi' Ali. Engko' bânni apah, rèya ko’ èsoro nèngghu juko', jeriya bâdâ Rahmad.

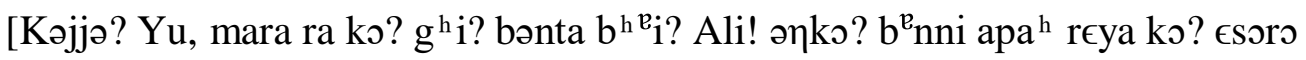
n€ฑg ${ }^{\mathrm{h}} \mathrm{u}$ juks?, jəriya $\mathrm{b}^{\mathfrak{E}} \mathrm{d}^{\mathfrak{e}}$ Rahmad. ]

'Tunggu Mbak, ayo ra aku masih bicara sama Ali. 'Saya disuruh melihat ikan, itu ada Rahmat.'

B: Majera ko'!

[Majəra ko?]

'Mau bayar saya' 
Tuturan deklaratif dalam kutipan ini digunakan untuk meralisasikan tindak imperatif yang dituturkan oleh $\mathrm{C}$ kepada B. C menghimbau B untuk mendatangi orang yang disebut namanya oleh $\mathrm{C}$, memahami perintah tersebut $\mathrm{B}$ memperjelas maksud dan tujuan kedatangannya. B tidak melakukan yang diinginkan oleh C. Tuturan tersebut dianggap santun, jika diukur menggunakan skala ketidaklangsungan. $\mathrm{C}$ menggunakan nonimperatif untuk mengungkap tindak imperatif permintaan yang ditujukan kepada B. Diukur menggunakan jarak sosial, tuturan tersebut juga dianggap santun.

\subsection{Tindak Imperatif Menggunakan Kalimat Interogatif}

Di samping direalisasikan dengan kalimat imperatif dan kalimat deklaratif, tindak imperatif dalam interaksi sosial di pasar ikan Kota Kulon, Bondowoso juga direalisasikan dengan kalimat interogtaif atau kalimat tanya. Hal ini seperti tampak dalam kutipan berikut.

Konteks: tuturan disampaikan oleh pengecer yang disimbolkan dengan C (usia 42 tahun) kepada pembeli yang disimbolkan dengan B (usia 36 tahun). Kedua penutur telah lama kenal, tuturan terjadi pada pukul 12.25 WIB. Suasana pasar ramai. C ditugaskan oleh pedagang untuk melihat ikan yang ditawarkan oleh pedagang lain. B yang melihat $\mathrm{C}$ berjalan menuju arah utara, langsung menyapa dan ingin membayar setoran ikan.

Tuturan:

B: Si, majera ko'!

[Si, majora ko?!]

'Si, saya mau bayar!'

C: Yu, ka Ali ghellun yâ?? Ko' ghi' ka dâjâ nèngghua juko'.

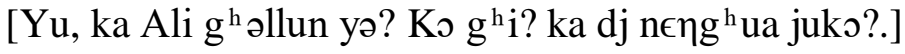

'Mbak, ke Ali dulu ya? Saya ,masih mau ke utara.'

B: Iyâh, dimma?

[Iy' h, dimma]

'Iya, dimana?'

Tuturan interogatif dalam kutipan tersebut digunakan untuk merealisasikan tindak imperatif C kepada B. C menghimbau B untuk melakukan transaksi jual beli kepada pengecer yang disebut oleh C. B yang memahami hal tersebut melakukan suatu tindakan sesuai kehendak C. Tuturan tersebut dianggap santun, jika diukur menggunakan skala ketidaklangsungan. C menggunakan nonimperatif untuk mengungkap tindak imperatif yang ditujukan kepada B. Jika diukur menggunakan jarak sosial, tuturan tersebut juga dianggap santun, karena C dan B memiliki status sosial dekat.

Dari kalimat-kalimat yang digunakan sebagai pengungkap tindak imperatif diketahui bahwa realisasi kesantunan dalam tindak imperatif berbeda-beda, baik secara kelangsungan tuturan maupun dari partikel yang digunakan. Partikel yang digunakan sebagai penegas dalam mengungkap tindak imperatif di antaranya yâh, $r a$ dan ko. Tindak imperatif menggunakan partikel yah biasanya digunakan oleh atasan kepada bawahan, jika atasan tersebut menemui satu kesalahan yang dilakukan oleh bawahan atau antarkawan, misalnya antara pembeli dan pengecer ketika pengecer menawarkan ikan dengan jumlah lebih banyak, pembeli menggunakan tindak 
imperatif dengan menggunakan kalimat interogatif. Maksud penggunaaan partikel yah sebagai penghalus tuturan, seperti pada contoh kutipan berikut.

B: Si bitong, Si!

[Jəriya bitoๆ, Si]

'Si hitung, Si!'

C: Ta' korang Sri, kibè be-bellu' la yâh?

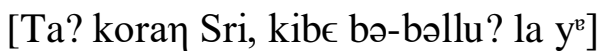

'Tidak kurang Sri, bawa delapan ya?'

B: Ella jha' nya'- benya' Si, pa'empa' bei lah yah? Tako'ta' abi'.

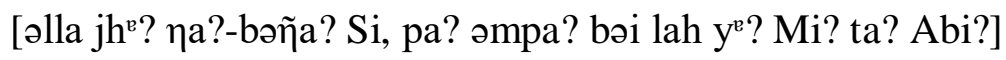

'Jangan banyak-banyak Si, empat saja ya? Takut tidak habis.'

C: Iyâh.

[Iy $\mathrm{L}$ ]

'Iya.'

Tindak imperatif menggunakan partikel ra biasanya digunakan oleh atasan kepada bawahan, atau dapat digunakan oleh sesama teman. Munculnya partikel tersebut ketika penutur mengetahui bahwa lawan tuturnya telah melakukan dua kali kesalahan, misalnya antara pembeli dan pengecer. Pembeli ingin membayar uang setoran ikan, namun pengecer memiliki letak yang berjauhan. Pembeli meminta pengecer untuk menghampirinya, namun pengecer tidak mengindahkan tuturan pembeli, sehingga untuk mempertegas tuturannya, pembeli menggunakan partikel ra. Penggunaan partikel $r a$ dalam tindak imperatif dianggap kurang santun.

Pembeli: Si, majera ko'! ma' ger ce' jeunna, dhina' ra!

[Si, majera ko?, ma? ger ce? Jeuna, $\mathrm{d}^{\mathrm{h}}$ ina? ra]

'Si, saya mau bayar, kok sampai sangat jauh, sini!'

Pengecer: Dhante' Yu, kejjâ'!Gi' bâdâ sè majer.

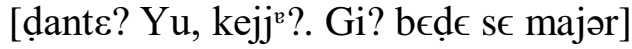

'tunggu mbak, sebentar! Masih ada yang bayar!'

Tindak imperatif menggunakan partikel ko biasanya digunakan oleh atasan kepada bawahan, atau dapat digunakan oleh sesama teman. Munculnya partikel tersebut ketika penutur mengetahui bahwa lawan tuturnya telah melakukan kesalahan berulang-ulang, misalnya antara kuli kepada kuli. Para kuli diperintah oleh pedagang agar tidak menurunkan ikan ketika mobil pengangkut ikan tiba. Pesan tersebut dilaksanakan oleh kuli 1, namun sebaliknya pada kuli 2, ia menghampiri mobil pengangkut ikan. Mengetahui hal tersebut kuli mengingatkan kuli 2 mengenai pesan yang disampaikan oleh pedagang. Penggunaan partikel ko dalam tindak imperatif tersebut dianggap kurang santun.

Kuli 1: Elun...elun..., jhâ' èpatoron ghelun ko!

[əlun...əlun..., j ${ }^{\text {e }}$ ? єpetoron ghəlun kə.]

'tunggu...tunggu..., jangan diturunkan dulu!'

Kuli 2: iyâh la taoh. 
[iy'h la taoh.]

'iya sudah tahu.'

Dalam penelitian ini ditemukan penggunaan partikel yah pada tindak imperatif yang dituturkan dengan menggunakan kalimat imperatif, interogatif, dan deklaratif. Penggunaan partikel tersebut lebih bebas karena partikel tersebut dimaksudkan untuk memperhatus tuturan. Berbeda dengan partikel $r a$ dan $k o$ yang digunakan dalam kaliamt imperatif saja. Hal ini disebabkan karena partikel tersebut dimaksudkan untuk mempertegas tuturan agar lawan tutur melakukan suatu tindakan sesuai dengan kehendak penutur. Selain itu, hasil penelitian di pasar ikan Desa Kota, Kabupaten Bondowoso, menunjukkan bahwa tidak ditemui partikel yah, $r a$, dan ko yang digunakan oleh bawahan terhadap atasan.

\section{Kesimpulan}

Hasil penelitian nenunjukkan bahwa terdapat delapan cara mewujudkan tindak imperatif dalam interaksi di pasar ikan di Kota Kulon, Bondowoso, yaitu menggunakan kalimat imperatif (1) perintah, (2) ajakan, (3) larangan, (4) permintaan, (5) suruh, (6) ngelulu, (7) kalimat deklaratif, dan (8) menggunakan kalimat interogatif. Dalam penerapannya, tindak imperatif tidak hanya dilakukan dengan menggunakan kalimat imperatif melainkan dapat menggunakan kalimat deklaratif dan kalimat interogatif. Ketiga tindak tutur tersebut memiliki tingkat kesantunan yang berbeda-beda. Tindak imperatif dianggap tidak santun, jika penyampaianya dilakukan secara langsung, terutama oleh bawahan kepada atasan, misalnya antara pengecer kepada pedagang ikan. Demikian pula, tindak imperatif dikatakan kurang santun., jika disampaikan dalam bentuk kalimat imperatif oleh bawahan kepada atasan, misalnya antara kuli dan pengecer.

Penggunaan tindak imperatif tidak ditemukan dalam bentuk penggunaan kalimat imperatif oleh bawahan kepada atasan. Kalaupun ada biasanya tindak imperatif direalisasikan dalam bentuk deklaratif dan interogatif kalimat deklaratif dan interogatif. Tiga bentuk kalimat yang digunakan sebagai pengungkap tindak imperatif memiliki tingkat kesantunan yang berbedabeda, baik secara kelangsungan tuturan maupun dari partikel yang digunakan. Partikel yang digunakan sebagai penegas dalam mengungkap tindak imperatif diantaranya yâh, ra dan $k o$. Partikel yah biasanya digunakan oleh atasan kepada bawahan, baik digunakan menggunakan kalimat imperatif, interogatif dan deklaratif. Partikel $r a$ dianggap kurang santun, partikel tersebut sering digunakan oleh atasan kepada bawahan atau antarkawan, sering muncul pada kalimat imperatif. Selain itu, terdapat partikel $k o$ yang dianggap kurang santun jika dibandingkan dengan partikel yah dan $r a$. Partikel tersebut biasa digunakan oleh atasan kepada bawahan atau antarkawan, partikel tersebut sering muncul pada penggunaan kalimat imperatif. Dalam penelitian jarang ditemukan partikel yah, $r a$, dan $k o$ yang digunakan oleh bawahan terhadap atasan.

\section{Daftar Pustaka}

Chaer, A. 2010. Sosiolinguistik: Pengenalan Awal. Jakarta: PT Rineka Cipta.

Ibrahim, A. S. 1993. Kajian Tindak Tutur. Surabaya: Usaha Nasional. 
Kesantunan Imperatif pada Masyarakat Madura di Pasar Ikan Desa Kota Kulon, Kabupaten Bondowoso (Retno Dyah Susilaningtyas, Bambang Wibisono, Budi Suyanto)

Kunjana, R. R. 2005. Kesantunan Imperatif Bahasa Indonesia. Jakarta: Erlangga.

Kunjana, R. R. 2009. Sosiopragmatik. Yogyakarta: Erlangga.

Leech, G. 1993. Prinsip-Prinsip Pragmatik. Jakarta: Penerbit Universitas Indonesia (UI-Press)

Mulyana. 2005. Kajian Wacana: Teori, Metode dan Aplikasi Prinsip-Prinsip Analisis Wacana. Yogyakarta: Tiara Wacana.

Pateda, M. 1987. Sosiolinguistik. Bandung: Angkasa.

Rohmadi, M.. 2004. Pragmatik: Teori dan Analisis. Yogyakarta: Lingkar Media.

Sofyan, A. 2016. Bahasa Madura. Yogyakarta: Jogja Bangkit Publisher (Anggota IKAPI)

Sofyan, Wibisono, Mahmud dan Subiyatningsih. 2008. Tata Bahasa Bahasa Madura. Surabaya: Balai Bahasa Surabaya.

Sudaryanto. 1993. Metode dan Aneka Teknik Analisis Bahasa: Pengantar Penelitian Wahana Kebudayaan secara Linguistik. Yogyakarta: Duta Wacana University Press.

Universitas Jember. 2010. Pedoman Penulisan Karya Ilmiah. Edisi Ketiga, Cetakan Kedua. Jember: Jember University Press.

Wibisono, B. dan A. Sofyan. 2008. Perilaku Berbahasa Orang Madura. Sidoarjo: Balai Pustaka Surabaya.

\section{Jurnal}

Sofyan, A. 2007. Dialek dan tingkat tutur dalam Bahasa madura. Jurnal Ilmiah Kebahasaan. $2(1): 1-9$.

\section{Skripsi}

Faizal, A. 2012. Penanda Imperatif Bahasa Madura di Kabupaten Sumenep. Skripsi. Jember: Jurusan Sastra Indonesia Fakultas Sastra Universitas Jember.

Rasidi, M. 2014. Kesantunan Imperatif dalam Lingkungan Keluarga Masyarakat Madura di Kecamatan Sumbermalang Kabupaten Situbondo. Skripsi. Jember: Jurusan Sastra ndonesia Fakultas Sastra Universitas Jember. 


\section{Internet}

Munfaida, S., B. Wibisono, dan A. Subaharianto. 2014. Kesantunan imperatif dalam interaksi jual beli di pasar tradisional Desa Kecik Kecamatan Kencong Kabupaten Jember. http://repository.unej.ac.id/bitstream/handle/123456789/68113/Siti\%20Munfarida.pdf? sequence $=1$. [Diakses pada 26 Januari 2017]

Saputra, I. W. G. M., I. N. Martha, dan I. W. Ratna. 2014. Imperatif tuturan guru untuk memotivasi siswa dalam pembelajaran Bahasa Indonesia di Kelas VII SMP Negeri 1 Singaraja. Jurnal Pendidikan dan Sastra Indonesia. 2(1).http://download.portalgaruda.org/article.php?. [Diakses pada 26 Januari 2017]. 